\title{
Dynamic Models of the Creative Industries' Entities in the Globalized Environment
}

\author{
Mária Trúchliková ${ }^{1}$, and Mária Kmety Barteková1,*, \\ ${ }^{1}$ University of Economics, Faculty of Business Management, Department of Business Economy, \\ Dolnozemská cesta 1, 85235 Bratislava, Slovakia
}

\begin{abstract}
.
Research background: The creative industries, from this point of view, have dynamic and not just static economic value. They supply the economic growth and development over and above their addition to culture and society.

Purpose of the article: The aim of this paper is to analyse the two models that present the two potential answers to the research question: namely expansion and modernization. This paper will summarize these two models and assemble a sample of remaining evidence to set up the process of separating among them.

Methods: However, this paper does not seek a complete study. For that, a much more precise approach to modelling, data and statistical analysis would be required. We provide here only a concept of the classes of models suggested and an explanation of how different sorts of data might be applied to them. The model of economic growth actively involves the creative industries in the growth of the whole economy. The second model - model of innovation as suggested for the effect of science, education and technology in the national systems of innovation approach. The creative industries, in the second model, come from and integrate change in the knowledge base of the economy.

Findings \& Value added: We proposed the two possible primary relations between the creative industries' entities and the rest of the economy. We define the relation of each model to various theoretical foundations and the relevant policy framework in each situation.
\end{abstract}

Keywords: Creative industries; Dynamic Models; Globalized economy

JEL Classification: $L 89 ; O 30 ; Z 10$

\footnotetext{
* Corresponding author: maria.bartekova@euba.sk
} 


\section{Introduction}

The Slovak economy is highly globalized. According to the latest data, the share of exports relative to GDP was more than $94 \%$. The integration of the Slovak Republic into the global market has reinforced the inflow of foreign direct investment into a small number of sectors, followed by enormous technology transfers. To balance such expansions, it is necessary to enlarge internal sources of development, the economic self-sufficiency of regions and national research and development. Development based on innovations is unattainable without a creative and valuable workforce, therefore Slovakia must pay special attention to increasing its capacity to support and attract talent. Greater involvement of the private sector is also crucial as the share of research and development spending by private businesses in Slovakia is the lowest in the European Union.

The globalization of business presents great opportunities for companies to stay competitive, expand their reach to new markets and increase efficiency $[1,2]$. Globalization includes a much wider field than just flowing of goods, services or capital. Often referred to as the globalization concept map, some examples of globalization are mentioned bellow:

- Economic globalization: is the development of trade systems within transnational actors such as corporations or Non-Governmental institutions.

- Financial globalization: can be linked with the rise of a global financial system with international financial exchanges and monetary exchanges.

- Cultural globalization: refers to the interpenetration of cultures which, as a consequence, means nations adopt principles, beliefs, and costumes of other nations, losing their unique culture to a unique, globalized supra-culture.

- Political globalization: the development and growing influence of international organizations.

- Sociological globalization: information moves almost in real-time, together with the interconnection and interdependence of events and their consequences.

- Technological globalization: the phenomenon by which millions of people are interconnected thanks to the power of the digital world via various online platforms.

- Geographic globalization is the new organization and hierarchy of different regions of the world that is constantly changing.

- Ecological globalization: accounts for the idea of considering planet Earth as a single global entity - a common good all societies should protect since the weather affects everyone and we are all protected by the same atmosphere.

For purpose of our research, we will be mostly focusing to the economic and financial globalized environment.

Dynamic models are essential for understanding the system dynamics in open-loop or for closed-loop control. These models are either derived from data or from more fundamental relationships that rely on knowledge of the process or the environment. A combination of the two approaches is often used in practice where the form of the equations are developed from fundamental balance equations and unknown or uncertain parameters are adjusted to fit process data. The system dynamics model studies the interactions between three main dimensions: the Slovak economy, the economic value of the Creative Industries and utility welfare. These factors interact with each other in a complex manner, leading to coevolutionary growth of the economic system. Developing economies that are able to activate and support synergies among their main growth engines can achieve a faster catch up process and more sustained income per capita level in the long-run than countries characterized by weak co-evolutionary dynamics [3 - 5].

In the introduction, we state the socio-economic indicators for the Creative Industries' Entities. Almost 4,000 units were identified on the Slovak market, which, based on reported 
business activities, can fall within the creative industries. In Slovakia, most companies operating in the CCI area are SMEs, micro-enterprises or people working as self-employed. When compared to the total number of SMEs and large enterprises in Slovakia, entities doing business in the creative industries account for $6.2 \%$ of the corporate sector. By the study of Petrikova, Vanova and Borsekova [6], the area of software development and computer consultancy can be clearly designated as the area with the greatest potential and market share. In the context of globalization, innovations are clearly bearers of a potential enterprises' competitiveness, start-ups are consider as their most important sources [7]. Start-ups in the area of software development and software consultancy are based on the human capital designed to create novel products, services, processes, and bring them to the markets. The basic precondition for meaningful growth of start-ups in the mentioned area is favourable business environment and framework supporting innovative entrepreneurship including access to external sources of financing [7]. Total revenues in the creative industries in 2019 moved to the edge of 1.78 billion EUR, representing nearly $4 \%$ of all sales of the Slovak economy. According to official statistics, the sector employs over 73 thousand people, representing about $4 \%$ of total employment in the Slovak Republic. For the development of the creative industry it is essential to complete the necessary infrastructure. This infrastructure should include creative centres designed to support and develop creativity to generate unique concepts and solutions. They should develop tailormade educational and advisory activities to stimulate their economic growth by generating and supporting the implementation of new business models [6]. However, new business models impose major challenges to managers who rely on incomplete cognitive representations while attempting to understand the environmental dynamics that determine a business model's prospective performance [8].

In macroeconomic modelling (dynamic models of the creative industries included), it is important to detect whether there is nonlinearity in terms of growth, for misinterpretation of the data could guide towards model misspecification by using linear models. A failure to recognize and deal with the presence of nonlinearity in the generating mechanism of a time series can often lead to poorly behaved parameter estimates and models who miss significant serial dependencies altogether [9].

According to Cerisola (2019), the potentially positive impact of cultural heritage and the creative industries in general, on economic development has gained more and more attention throughout different disciplines [10]. We have focused on the utility value generated by the creative industries measured by the indicator value added.

\section{Methods}

The subchapters mentioned bellow provides the information about research aim, the precise description of the research object and the methodology used in this paper.

\subsection{Research Aim}

The aim of the paper is to propose two dynamic models describing the behaviour represented by growth and innovation of the Creative Industries in Slovakia. The following research questions were articulated:

- Research question no. 1: How could be growth of the economy driven by the creative industries in Slovakia?

- Research question no. 2: What is the dynamic relation between the creative industries' innovation and the rest of the Slovak economy? 


\subsection{Object of the Research}

The object of scientific research is the sector of Slovak economy - the creative industries. The cultural and creative sectors are developing in Slovakia along with traditional sectors. The firms in creative sectors are considerably concentrated in space and create clusters. The Bratislava region is one of prominent EU regions from the point of view of concentration of employment in the creative sectors since in this region approximately $5.01 \%$ of the labour force work in these sectors, pointing out at significant specialisation. Moreover, $46 \%$ of all firms in the creative sectors are seated in the Bratislava region, of that $91 \%$ directly in Bratislava. Design and computer programming can be considered as the most prospective orientation of the creative industries in Slovakia. In 2015, the number of companies in CCI area was approximately 20,299 units, of which 10,218 were legal entities and 10,081 individuals. In 2015 the number of employees in culture and creative industries was 62,914 that represents full time jobs and different kinds of part time jobs and contracts in the main sectors of CCI as well $(43,812$ of the number mentioned above presents only full time jobs in the main sectors of CCI). As for the average employee per CCI company, it is approximately $2,4[6]$.

\subsection{Methodology}

In the beginning of this subchapter, we have to explain the symbols representing various economic indicators. $\mathrm{Y}$ is representing the economic value (output) of the whole economy in Slovakia and the economic value of the creative industries is defined as CI. The master equation is $\mathrm{CI}=\mathrm{A} * \mathrm{Y}$. This just says that the creative industries comprise some given fraction (A) of all economic activity. In a static model, this measurement is treated as the "significance" of the sector.

Our starting axiom is that change in CI affects GDP (Y) in some way $(\Delta \mathrm{CI} \leftrightarrow \Delta \mathrm{Y})$. The two models proposed are the set of possible dynamic interrelations in which a change in CI activity has positive effect on the economy. We also assume that $d \mathrm{CI} / d \mathrm{Y}=0$, meaning that economic growth affects the creative industries no differently to other industries, or technically that income elasticity is unitary. We strongly suspect this not to be the case, but rather that growth in income disproportionately effects demand for the output of the creative industries, but we shall set that aside here. Policy is analysed in terms of whether change in the creative industries changes aggregate utility welfare (or utility, U). Again, we presume $d \mathrm{U} / d \mathrm{CI}$ can increase, decrease or leave utility unaffected.

The model 1 explicitly proposes a positive economic relation between growth in the creative industries and growth in the aggregate economy, such that $d \mathrm{Y} / d \mathrm{CI}>0$. There are many possible explanations, but all are some variation upon either the notion that the creative industries introduce novel ideas into the economy that then percolate to other sectors (e.g. design-led innovation), or that the creative industries facilitate the adoption and retention of new ideas or technologies in other sectors.

Involvement of the creative industries in the growth of the economy can occur in two principle ways: supply-side and demand-side. The supply-side interpretation of this model emphasizes the export of new ideas from CI to Y. The demand side interpretation emphasizes how growth in $\mathrm{Y}$ causes a proportionate increase in demand for CI services.

The model 1 is defined by these two formulas:

$$
\begin{aligned}
& \frac{d Y}{d C I}>0 \\
& \frac{d U}{d C I} \geq 0
\end{aligned}
$$


If the model 1 is true, then there is a clear economic case for redirecting resources, not just for the benefit of the creative industries per se, but for the benefit of all. The creative industries, in this view, are clear winners to be backed. Evidence for this model would come from association of the creative industries with growth. This would accrue not just in jobs and commodities, but in new types of jobs and new sorts of commodities and services. The second model proposes the creative industries as growth drivers not because of operational expenditure multipliers, but due to their role in the adoption, retention and absorption of new ideas and technologies.

The model 2 is described by the formula 3 and 4 :

$$
\begin{aligned}
& \frac{d Y}{d C I} \text { undefined } \\
& \frac{d U}{d C I} \text { open }
\end{aligned}
$$

Rather than thinking of the creative industries as an economic subset "driving" growth in the whole economy, as in model 1 , the creative industries may not be well characterized as an industry per se, but rather as an element of the innovation system of the whole economy.

Model 2 hypothesizes the relationship between the creative industries and the rest of the economy in a different way. This model effectively rejects the initial statics-to-dynamics master equation $\mathrm{CI}=\mathrm{A} * \mathrm{Y}$. Instead, it re-conceptualizes the creative industries as a higherorder system that operates on the economic system. The creative industries, in this view, originate and coordinate change in the knowledge base of the economy. In consequence they have crucial, not marginal, policy significance. In model 2 , the significance of the creative industries is not in terms of their relative contribution to economic value (models 1), but due to their contribution to the coordination of new ideas or technologies, and thus to the process of change. In this view, the creative industries are mis-specified as an industry per se, and better modelled as a complex evolving system that derives its economic value from the facilitation of economic evolution and the process of innovation. The creative industries might in this sense be better understood as a kind of industrial entrepreneurship operating on the consumer side of the economy. In this case, we are dealing with an evolutionary model of the creative industries. Change in the creative industries therefore produces structural and not just operational change in the economy. New opportunities and possibilities will thus emerge of which the welfare effect cannot be known in advance. This is the typical situation of economic evolution as the origination, adoption and retention of generic novelty $[11,12]$. According to model 2, the creative industries do not drive economic growth directly, as might a boom in the primary resource sector or the housing market for example, but rather facilitate the conditions of change in the economic order. If model 2 is true, then, the creative industries are part of the innovation system driving and coordinating the growth of knowledge process that underpins economic evolution.

\section{Results and Discussion}

The average value of Economic globalisation index for Slovakia during the period 1993 2017 was 68.95 points with a minimum of 48.1 points in 1995 and a maximum of 83.07 points in 2017. For comparison, the world average in 2017 based on 188 countries is 59.06 points [13]. The Economic Globalization Index has two dimensions. First, it measures the economic flows between Slovakia and the rest of the world in terms of international trade and international investment. Second, it measures the restrictions to trade and investment such as tariffs and capital controls on international investment. Each dimension is based on several variables that are combined in one overall index that ranges from 0 to 100 . 


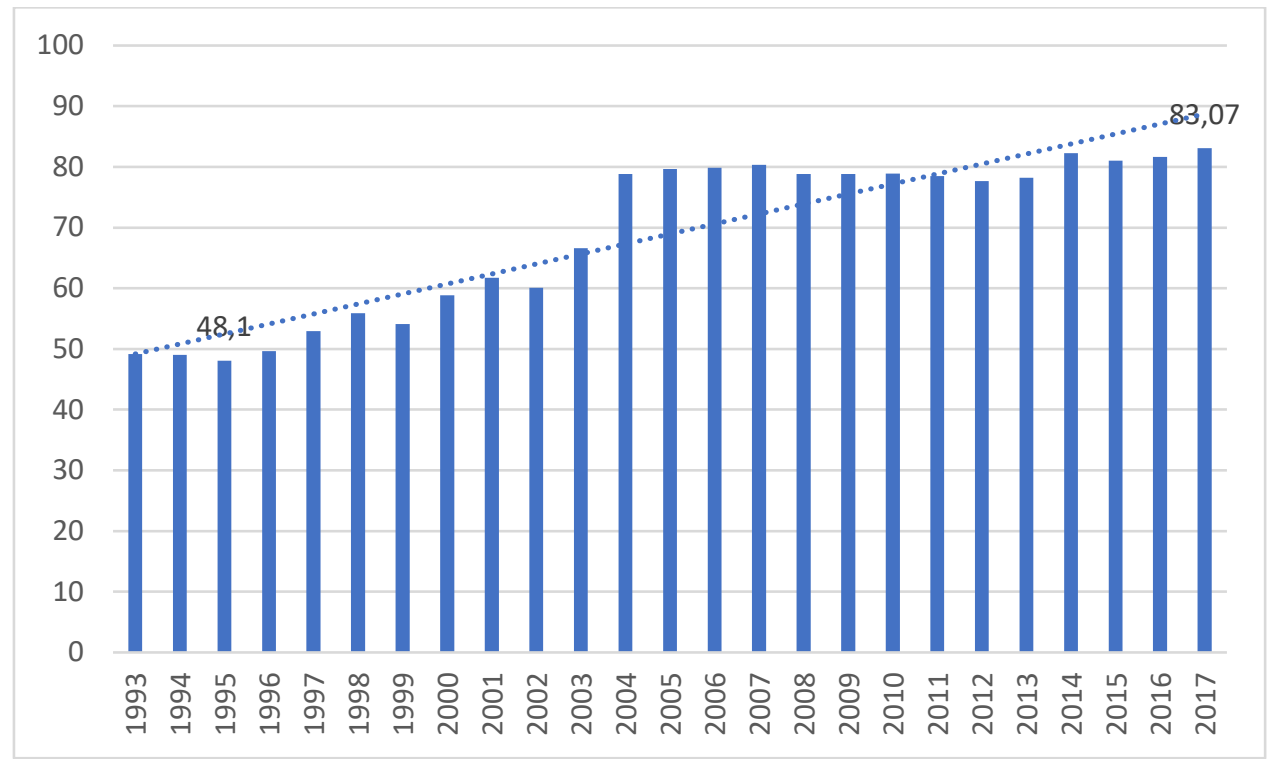

Fig. 1. The Economic Globalization Index in Slovakia (1993-2017)

The values of the Social Globalization Index from 1993 to 2017 are shown in figure 2. The average value for Slovakia during that period was 75.51 points with a minimum of 59.26 points in 1993 and a maximum of 82.84 points in 2017. One can see that for both indicators, we follow the growing trend [13].

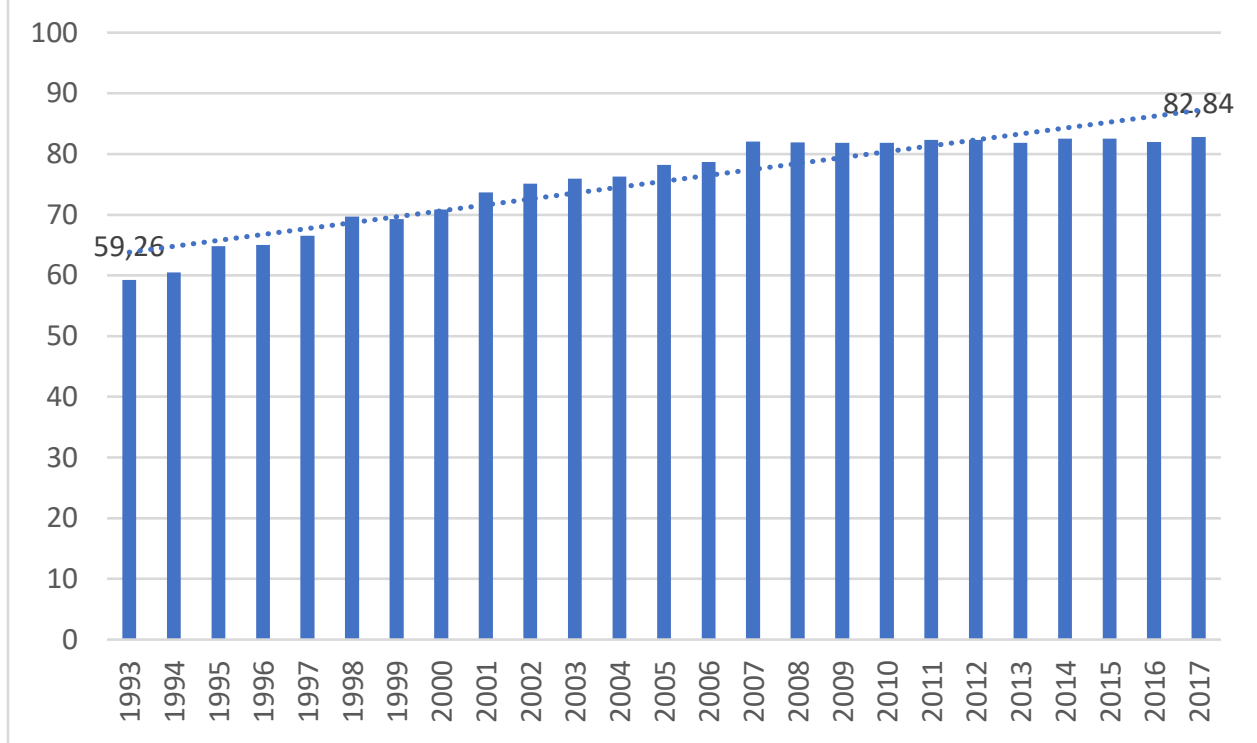

Fig. 2. The Social Globalization Index in Slovakia (1993-2017)

Table 1 contains the results of our analysis and data modelling based on the data obtained from Eurostat. The fourth column contains the turnover produced by the creative industries in Slovakia. The highest turnover (14 115 million euro) had been reached by the creative industries in 2019 [14]. The model 1 related to the growth, the creative industries are essentially a 'merit good' sector that produces cultural commodities that are welfare enhancing ( $d \mathrm{U} / d \mathrm{CI} \geq 0)$, but that are only economically viable with a transfer of resources 
from the rest of the economy $(d \mathrm{Y} / d \mathrm{CI}>0)$. The model 1 is not valid in Slovakia because the condition $(d \mathrm{U} / d \mathrm{CI} \geq 0)$ was not fulfilled. With improved and continual cultural statistics, also a more developed analysis would be possible.

Tab. 1. The results of the model 1 and the model 2

\begin{tabular}{|r|r|r|r|r|r|}
\hline Year & \multicolumn{1}{|c|}{$\mathbf{Y}$} & \multicolumn{1}{|c|}{$\mathbf{U}$} & \multicolumn{1}{|c|}{ CI } & \multicolumn{1}{|c|}{$\boldsymbol{d}$ Y/dCI } & \multicolumn{1}{c|}{$\boldsymbol{d}$ /dCI } \\
\hline $\mathbf{2 0 1 0}$ & 68093,0 & 418,3 & 9777 & 0,0005127 & 0,031982942 \\
\hline $\mathbf{2 0 1 1}$ & 70043,4 & 433,3 & 10246 & 0,0007531 & $-0,119220056$ \\
\hline $\mathbf{2 0 1 2}$ & 71371,3 & 476,1 & 9887 & uncountable & uncountable \\
\hline $\mathbf{2 0 1 3}$ & 71850,1 & 469,2 & unavailable & uncountable & uncountable \\
\hline $\mathbf{2 0 1 4}$ & 73827,8 & 457,4 & unavailable & uncountable & uncountable \\
\hline $\mathbf{2 0 1 5}$ & 77387,7 & 452,6 & 11690 & 0,0006086 & $-0,013011152$ \\
\hline $\mathbf{2 0 1 6}$ & 79030,9 & 438,6 & 12766 & 0,0004154 & 0,072202591 \\
\hline $\mathbf{2 0 1 7}$ & 81438,4 & 499,9 & 13615 & 0,0003151 & uncountable \\
\hline $\mathbf{2 0 1 8}$ & 84611,9 & unavailable & 13789 & 0,0004928 & uncountable \\
\hline $\mathbf{2 0 1 9}$ & 86641,3 & unavailable & 14115 & 0,023303 & uncountable \\
\hline
\end{tabular}

The model 2 is based on the premise that $(d \mathrm{Y} / d \mathrm{CI})$ undefined and at the same $(d \mathrm{U} / d \mathrm{CI})$ open; and proposes a positive economic relation between innovation in the creative industries and innovation in the aggregate economy. Based on the results of our research, we can conclude that according to the premises model 2 is valid in the Slovak economic environment. The limitations of this research are in the missing data from few years.

\section{Conclusions}

We cannot predict with confidence whether the coming year will bring a higher or a lower level of globalization. But we can safely say that international flows and the constraints that borders and distance impose upon them will both continue to matter [15]. So, the biggest winners regardless of whether globalization goes up or down, are likely to be companies that embrace globalization's complexity rather than purely local or global visions of their business environments. Slovakia is an open economy that is widely interconnected with other countries. This statement is supported by the fact that almost half of Slovakia's economic activity (GDP) is dependent on foreign markets.

The model 1 based on the growth was not confirmed and it is not valid for the Slovak globalized environment. On the other hand, the model 2 linked to the innovation of the creative industries and the rest of the economy is predicting the dynamic behaviour of the creative industries' entities. Yet in both cases, policy should properly treat the creative industries as a 'special sector'. This is not because it is economically significant, but because it powers the innovation of other sectors.

This paper is the output of the scientific grant VEGA n. 1/0340/19 "The Entrepreneurial Dimension of Creative industries in the Context of Innovation and Smart Growth (50\%) and the internal grant project of the University of Economics in Bratislava (Faculty of Business Management) no. I-20-101-00 called "Research of Creative Industry Enterprises with regard to Their Life Cycle in the Slovak Republic" (50 $\%)$. 


\section{References}

1. Kalecki, M. (1990). Capitalism: Business cycles and full employment. Collected works Vol. I. Oxford: Clarendon Press.

2. Kramarova, K. (2016). Business clusters and initiatives as a tool of promoting competitiveness in a globalizing environment. In T. Kliestik (Eds.), $16^{\text {th }}$ International Scientific Conference Globalization and Its Socio- Economic Consequences (pp. 10611068). Zilina: University of Zilina.

3. Brenner, T., Duschl, M. (2018). Modeling Firm and Market Dynamics: A Flexible Model Reproducing Existing Stylized Facts on Firm Growth. Computational Economics, 52(3), 745-772.

4. Castellacci, F. (2018). Co-evolutionary growth: A system dynamics model. Economic Modelling, 70(1), 272-287.

5. Hisamatsu, T. (2018). Robert Torrens and the Ricardian model of dynamic equilibrium growth. The European Journal of the History of Economic Thought, 25(2), 203-226.

6. Petrikova, K., Vanova, A., Borsekova, K. (2015). The role of creative economy in Slovak Republic. AI \& Society, 30(2), 271-281.

7. Achimska, V. (2020). Start-ups, bearers of innovation in globalizing environment and their valuation. SHS Web of Conferences, 74, 01001.

8. Moellers, T., von der Burg, L., Bansemir, B., Pretzl, M., Gassmann, O. (2019). System dynamics for corporate business model innovation. Electronic Markets, 29(3), 387-406.

9. Skare, M., Tomic, D., Rochon, M.P. (2019). Testing Nonlinear Dynamics in Terms of Trade with Aggregated Data: Implications for Economic Growth Models. Inzinerine Ekonomika-engineering Economics, 30(3), 316-325.

10. Cerisola, S. (2019). A new perspective on the cultural heritage-development nexus: the role of creativity. Journal of Cultural Economics, 43(1), 21-56.

11. Waldfogel, J. (2020). Dining out as cultural trade. Journal of Cultural Economics, 44(2), 309-338.

12. Wusrt, B. (2019). Globalization and Sustainability of Regions: The Role of Cultural and Creative Industries in Cultural Policies and their Implications for Regional Development - A Case Study of the Czech Republic. SHS Web of Conferences, 74, 04032.

13. ETH Zürich, (2020, 23 July). KOF Globalisation Index. https://kof.ethz.ch/en/forecastsand-indicators/indicators/kof-globalisation-index.html

14. Eurostat, (2020, 01 August). Value added and turnover of enterprises in the cultural sectors by NACE Rev. 2 activity.

https://ec.europa.eu/eurostat/databrowser/view/cult_ent_val/default/table?lang=en.

15. Kloudova, J. (2009). Kreatívní ekonomika a jej měření. Ekonomický časopis 2009(9), 116. 